BNL-114457-2017-JA

File \# 95457

\title{
Design and performance of an $x$-ray scanning microscope at the hard $x$-ray nanoprobe beamline of the NSLS-II
}

\author{
E. Nazaretski \\ Submitted to: Journal of Synchrotron Radiation \\ October 5, 2017 \\ Photon Sciences Department \\ Brookhaven National Laboratory \\ U.S. Department of Energy \\ 86 ' 2 ( [2 IILFHRI $\square 6$ FLHQFH $\square 6$ \& $\square$

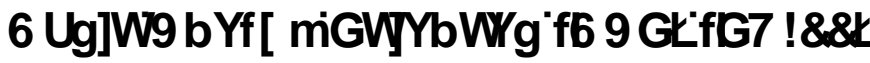

Notice: This manuscript has been authored by employees of Brookhaven Science Associates, LLC under Contract No. DE- SC0012704 with the U.S. Department of Energy. The publisher by accepting the manuscript for publication acknowledges that the United States Government retains a non-exclusive, paid-up, irrevocable, world-wide license to publish or reproduce the published form of this manuscript, or allow others to do so, for United States Government purposes. 


\section{DISCLAIMER}

This report was prepared as an account of work sponsored by an agency of the United States Government. Neither the United States Government nor any agency thereof, nor any of their employees, nor any of their contractors, subcontractors, or their employees, makes any warranty, express or implied, or assumes any legal liability or responsibility for the accuracy, completeness, or any third party's use or the results of such use of any information, apparatus, product, or process disclosed, or represents that its use would not infringe privately owned rights. Reference herein to any specific commercial product, process, or service by trade name, trademark, manufacturer, or otherwise, does not necessarily constitute or imply its endorsement, recommendation, or favoring by the United States Government or any agency thereof or its contractors or subcontractors. The views and opinions of authors expressed herein do not necessarily state or reflect those of the United States Government or any agency thereof. 


\title{
Design and performance of an x-ray scanning microscope at the Hard X-ray Nanoprobe Beamline of the NSLS-II
}

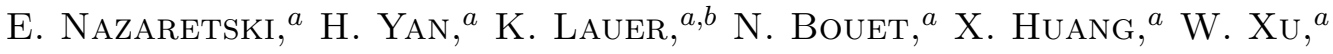 \\ J. Zhou, ${ }^{a}$ D. Shu ${ }^{c}{ }^{\mathrm{Y}} \mathrm{HwU}^{d}$ AND Y. S. $\mathrm{CHU}^{a}$ \\ ${ }^{a}$ Brookhaven National Laboratory, Upton, NY 11973 USA, ${ }^{b}$ SLAC National \\ Accelerator Laboratory, Menlo Park, CA 94025 USA, ' Advanced Photon Source, \\ Argonne National Laboratory, Argonne, IL 60439 USA, and dInstitute of Physics, \\ Academia Sinica, Taipei 11529, Taiwan
}

\begin{abstract}
We have designed, constructed and commissioned a hard x-ray scanning microscope installed at the Hard x-ray Nanoprobe beamline (HXN) of the National Synchrotron Light Source II. The microscope relies on compact, high stiffness, low heat dissipation approach and utilizes two types of nanofocusing optics. It is capable of imaging with $\sim 15 \times 15 \mathrm{~nm}^{2}$ spatial resolution using Multilayer Laue Lenses and $25 \times 26 \mathrm{~nm}^{2}$ resolution using zone plates respectively. Fluorescence, diffraction, absorption, differential phase contrast, ptychography and tomography are available as experimental techniques. The microscope is also equipped with a temperature regulation system which allows to vary temperature of a sample in the range between $90 \mathrm{~K}$ and 1000 K. The constructed instrument is open for general users and offers its capabilities to material science, battery research, and bioscience communities.
\end{abstract}




\section{Introduction}

X-ray microscopy is a mature characterization tool routinely applied to elucidate various questions in science, technology and engineering. (Shapiro et al., 2014, Holler et al., 2017, Yan et al., 2016) The high penetration power of x-rays allows for employing different characterization methods and revealing elemental composition, crystalline phases, strain distribution, oxidation states etc., in macroscopic and microscopic samples. To obtain comprehensive chemical and structural information at the nm-scale an x-ray microscope has to be equipped with adequate capabilities and acquire multiple datasets simultaneously. Full-field or scanning x-ray microscopes typically serve this purpose and compliment each other. (Liu et al., 2016) A number of x-ray scanning microscopes, nanoprobes, have been designed, constructed and commissioned in the recent years. (Winarski et al., 2012, Samogyi et al., 2015, Chen et al., 2014) Different types of nanofocusing optics can be used to achieve nm-scale spatial resolution imaging e. g. Fresnel Zone Plates (ZP), Kirkpatrick-Baez (KB) mirrors and waveguides Mohacsi et al., 2017, Chao et al., 2012, Mimura et al., 2010, Krueger et al., 2012, Silva et al., 2017). During the last decade Multilayer Laue Lenses were introduced as an alternative to ZP, they are capable of achieving high focusing efficiency in the hard x-ray regime (Kang et al., 2008, Conley et al., 2016, Morgan et al., 2015, Kubec et al., 2017, Kubec et al., 2017, Yan et al., 2014, Yan et al., 2011), and sub-15 nm focusing has been recently demonstrated (Huang 2013 et al.,, Morgan et al., 2015) In this work we present a hard x-ray scanning microscope, designed, constructed and installed at the Nanoprobe beamline of the National Synchrotron Light Source II. The microscope utilizes both MLLs (as high resolution nanofocusing optics) and a ZP for high-throughput, modest resolution imaging. The instruments supports fluorescence, tomography, differential phase contrast, diffraction and ptychography as imaging techniques and is open for general users.

IUCr macros version 2.1.10: 2016/01/28 


\section{Nanofocusing optics and modular concept of the microscope}

Multilayer Laue Lenses were proposed as an alternative approach to achieve nanofocusing and overcome the well-known 'aspect ratio problem' of zone plates when ZPs are used in the hard x-ray regime. A single MLL optic can be considered as a onedimensional zone plate which needs to satisfy the Bragg condition in order to perform line focusing. Moreover, it exploits dynamical diffraction effect to achive high numerical aperture and efficiency unattainable for conventional ZPs (Yan et al., 2007). A pair of linear MLLs needs to be aligned orthogonally with respect to each other to achieve point focusing. In total, eight degrees of motion (five linear and three rotational) are required to perform full alignment. Figure 1a shows a schematic of the MLL microscope. Orthogonality of two lenses plays a critical role in achieving ultimate performance. Angular misalignment introduces additional cross-phase term in the wavefront causing blurring of the focus. To quantify the degree of misalignment, a requirement has been established that $\gamma<\lambda f / 2 D^{2}$, where $\lambda$ is the wavelength, $f$ is the focal distance and $D$ is the aperture of a lens. In order to achieve $10 \mathrm{~nm}$ point focus, the misalignment $\gamma$ should remain below $0.01^{\circ}$ for a typical MLL with a focal length of $4 \mathrm{~mm}$ at $12 \mathrm{keV}$ photon energy and the aperture size $D$ of $40 \mu \mathrm{m}$. When fully aligned, both lenses have to maintain their respective angular positions throughout an experiment. Moreover, lateral positions of both lenses along the beam have to be maintained due to a finite depth of focus determined by the photon energy. The two lenses should also be aligned within the depth of focus along the longitudinal direction, which is $\sim 4 \mu \mathrm{m}$ at $12 \mathrm{keV}$. (Yan et al., 2008)

A schematic of a ZP scanning microscope is shown in Fig. 1b (ZP central beamstop is not shown). Since ZP is already a 2D focusing element, it does not require sophisticated alignment scheme as in the case of MLL. Moreover, focal distances for ZPs (depend on the photon energy and outermost zone width) may vary between 5 and $50 \mathrm{~mm}$ 
as opposed to sub-5 $\mathrm{mm}$ focal distances of the MLL optics. Significant differences in alignment schemes and the focal distances of ZPs and MLLs led to the development of two independent scanning microscopes, accommodated within the same vacuum chamber, as in Fig. 2.

High resolution (MLL microscope module) and moderate resolution (ZP microscope module) reside on top of a common invar table inside the vacuum chamber, see Fig. 2a. Both modules are mobile and can be manually brought into the beam without disconnecting any cables or optical fibers. Both modules are designed in such a way that they can accommodate the same set of fluorescence detectors (Vortex ME-3 and Bruker XFlash FlatQUAD 5060F) when brought into a working position downstream in the vacuum chamber. During operation, the other module is parked upstream and out of the beam, as shown in Fig. 2b. The vacuum chamber is equipped with three access doors which allow easy manipulation and re-positioning of both modules. The downstream door provides access for mounting of samples. It is equipped with a large $0.5 \mathrm{~mm}$ thick Beryllium window and allows diffraction measurements in the range of $-5^{\circ}$ to $65^{\circ}$ both vertically and horizontally. The vacuum chamber resides on top of a granite slab ( $\sim 4$ tons) installed in a vibration-isolated and temperature-controlled experimental hutch of the HXN beamline.

\section{High resolution Multilayer Laue Lens microscope module}

Design of the MLL microscope module greatly relies on the principles used in scanned probe microscopy systems which employ small form-factor, low heat dissipation, and stiff piezo actuators to achieve long-term stability and fine spatial resolution. (Mesares et al., 2011, Nazaretski et al., 2009, Lammle et al., 2010). Critical components of the MLL microscope module were prototyped and characterized beforehand (Shu et al., 2011, Nazaretski et al., 2013), with a number of instruments being constructed and IUCr macros version 2.1.10: 2016/01/28 
validated during the R\&D phase of the NSLS-II construction project. (Nazaretski et al., 2013, Shu et al., 2013, Nazaretski et al., 2014, Hwu et al., 2013) Development work culminated in the design and construction of the MLL microscope module shown in Fig 3. Panel a) in Fig 3 depicts the CAD model of the module with all key components enumerated. Fig. 3b is the photograph showing the instrument being installed inside the vacuum chamber of the HXN microscope. The instrument consists of different sub-components (assemblies) which perform well-defined functions, i.e. vertical MLL assembly (1), horizontal MLL assembly (2), Order Sorting Aperture (OSA) assembly, and sample stage assembly (4). All functional modules comprise of standard and customized piezo-driven actuators with optimized parameters of travel ranges, form factors and stiffnesses. Nine fiber-optic interferometer heads (5) are used to monitor and control lateral displacements of the vertical, horizontal MLLs and the sample stage. All interferometer heads are mounted on a monolithic invar reference frame to minimize thermal drifts of the critical components. Upon completion, the MLL microscope module was thoroughly characterized in the R\&D labs of NSLS-II followed by extensive x-ray performance evaluation at I-13 beamline of the Diamond Lighsource. More technical details describing the design, control and initial performance of the instrument can be found elsewhere. (Nazaretski et al., 2015)

Figure 4a demonstrates vibration spectrum of a fully loaded sample module inside the vacuum chamber of the HXN microscope. The main resonance frequencies are between 160 and $170 \mathrm{~Hz}$ with a typical amplitude of $\sim 1.5 \mathrm{~nm}$. For comparison, resonance frequencies of the vertical and horizontal MLL optics assemblies are in the range of 320 and $350 \mathrm{~Hz}$ and reveal sub-nm vibrational amplitudes. Vibrational performance of the MLL microscope module allows to execute reliable fly-scan measurements with $5 \mathrm{~nm}$ pixel size. Figure 4b,c demonstrate the Scanning Electron Microscope (SEM) and XRF measurements of a Pt test pattern. Scanning x-ray measurements were performed on 
a platinum L-edge, x-ray energy of $12 \mathrm{keV}$, exposure time of $0.2 \mathrm{~s}$ and $5 \mathrm{~nm}$ pixel size. Pt circles are $80 \mathrm{~nm}$ in diameter, have $20 \mathrm{~nm}$ thick walls and are $200 \mathrm{~nm}$ tall. Cross section through a test pattern (see Fig. 4c) shows individual rings and the spacing between them (less than $20 \mathrm{~nm}$ ) being well resolved indicating the resolution better than $15 \times 15 \mathrm{~nm}^{2}$. Demonstrated resolution is a convolution of a probe and a high aspect ratio test pattern. Detailed analysis of the focused beam size and exact imaging resolution will be presented elsewhere. We also measured the focused flux: it equals $5 \times 10^{8}$ photons/s at $12 \mathrm{keV}$ photon energy and $150 \mathrm{~mA}$ current in the storage ring. Thermal drifts can cause distortion of acquired fluorescence images if data acquisition spans over an extended period of time. We performed characterization measurements by repeatedly imaging the very same Pt test pattern with a 3 hour delay between the measurements. Inferred characteristic thermal drifts do not exceed $5 \mathrm{~nm} /$ hour in both vertical and horizontal directions.

\section{Moderate resolution zone plate microscope module}

Design of the Zone Plate microscope module follows similar concept and utilizes piezodriven and compact actuators, low heat dissipation components, interferometric monitoring and control. Figure 5 demonstrates the CAD model and photographs of the module, all key components are labeled. Four zone plates can be mounted on the ZP carriage simultaneously, this allows accommodation of various resolution optics; the outermost zone width and diameter of the used ZPs varies in the range from $25 \mathrm{~nm}$ to $50 \mathrm{~nm}$ and $150 \mu \mathrm{m}$ to $300 \mu \mathrm{m}$ respectively. Long travel range piezo-driven motion stage allows positioning of the zone plates along the x-ray beam covering the photon energy range from 5 to $25 \mathrm{keV}$. Long gold-plated reflectors (flatness better than $\lambda / 10$ ) are mounted on the zone plate carriage and allow interferometric motion and position control of the nanofocusing optics. Similarly to the MLL microscope module, interfer-

IUCr macros version 2.1.10: 2016/01/28 
ometer heads of the ZP microscope module are attached to the invar reference frame surrounding the ZP carriage and the sample stage. Zone plates are staggered and can be moved in and out of the beam during an experiment. Motorized central beam stop assembly is used to accommodate two beam stops of different diameter and is located upstream from the ZP assembly.

The sample assembly consists of a base piezo-crawling stage, a rotary stage, a parallel kinematic device and a sample scanner. The base invar stage has a low profile and a travel range of $20 \mathrm{~mm}$ in $\mathrm{X}$ and $\mathrm{Z}$ directions; it is used to align the center of the rotary stage with respect to the incoming x-ray beam. The rotary stage has been tested using characterization system described elsewhere (Xu et al., 2014) and demonstrated $<1 \mu \mathrm{m}$ combined rotational errors $50 \mathrm{~mm}$ above its top plate. The parallel kinematic device has a low profile (its height is only $45 \mathrm{~mm}$ ) and is used to bring the sample to the center of rotation. It is also used to perform angular adjustments for diffraction measurements. The sample scanner has a $40 \mu \mathrm{m}$ travel range in $\mathrm{X}, \mathrm{Y}$, and $\mathrm{Z}$ directions. It is equipped with the external capacitive and interferometric sensors for position encoding. Interferometers are primarily used for $2 \mathrm{D}$ scanning and characterization measurements while capacitive sensors are activated during 3D tomographic measurements. The OSA assembly consists of an X, Y, Z motion elements which are integrated into the invar reference frame and can follow the sample for optimal performance. Vibrational characteristics of the sample stage in the $\mathrm{X}$ - direction are shown in Fig. 6a. There is a number of broadened resonance peaks ranging from $100 \mathrm{~Hz}$ to 500 $\mathrm{Hz}$, with characteristic amplitudes less than $0.5 \mathrm{~nm}$. These resonances originate from a number of stages underneath the scanner. The scanner itself has a resonance frequency of $\sim 415 \mathrm{~Hz}$. Since the ZP microscope module is used for a moderate spatial resolution imaging experiments few nanometer integrated vibrational amplitudes do not affect the quality of the acquired data. Fig. $6 \mathrm{~b}, \mathrm{c}, \mathrm{d}$ demonstrate focusing performance of the

IUCr macros version 2.1.10: 2016/01/28 
ZP microscope module. The scanning probe imaging experiment was conducted at 8 keV photon energy. A star test pattern was scanned at a slightly de-focused plane of the zone plate with a $25 \mathrm{~nm}$ outermost zone width and $150 \mu \mathrm{m}$ diameter. The scan trajectory followed a Fermat spiral pattern covering $2 \times 2 \mu \mathrm{m}$ field of view with $50 \mathrm{~nm}$ circular increment step. At each scan position, the far-field diffraction data was collected by a Merlin pixel area detector with $55 \mu \mathrm{m}$ pixel size, placed $0.58 \mathrm{~m}$ away from the sample. A $192 \times 192$ array frame was cropped to feed into ptychography reconstruction process using difference map engine, which converges within 100 iterations and gives complex-valued images with $8.5 \mathrm{~nm}$ pixel size, as shown in Fig. 6d, e. Gaussian fittings of horizontal and vertical line plots give full-width-at-half-maximum focus sizes of $26 \mathrm{~nm}$ and $25 \mathrm{~nm}$, respectively. Measurements of the focused flux were conducted for one of the zone plates and revealed $1.17 \times 10^{9}$ photons $/ \mathrm{s}$ per $50 \times 50 \mathrm{~nm}^{2}$ at $10 \mathrm{keV}$ photon energy and $300 \mathrm{~mA}$ current in the storage ring.

\section{Temperature regulation system}

High spatial resolution x-ray imaging can greatly benefit from an instruments ability to vary pressure, magnetic field or temperature of a sample. (Huang et al., 2015, Uhlir et al., 2013, Deng et al., 2014) Dynamic processes and phase transitions can be explored revealing a full phase diagram of a particular sample. We have developed a temperature regulation system for the ZP microscope module of the HXN microscope which allows to change sample's temperature in the range from $90 \mathrm{~K}$ to 1000 K. The system is comprised of two independent setups: the cooling sample mount is used for the measurements in the temperature range between $90 \mathrm{~K}$ and $450 \mathrm{~K}$ and the heating sample mount operates in the temperature range of $300 \mathrm{~K}-1000$ K respectively. Figure 7 demonstrates the CAD models and the photographs of the cooling setup, with all major components listed. A helium (nitrogen-compatible) flow 
cryostat has been used to provide cooling for a sample mount. The cold finger of the cryostat is connected through a number of vibration isolation posts and braids to the cooling arm. The cooling arm extends to a sample assembly, (see Fig. 7b,d) and is linked to the sample mount through an oxygen free high conductivity (OFHC) copper (or graphite) cooling stripes. Stripes are used to optimize thermal conductivity and minimize stiffness when performing rotation during tomography measurements. The temperature difference between the cryostat tip and the sample mount assembly was measured to be $\sim 10 \mathrm{~K}$ when using nitrogen for cooling. The sample pin resides on top of a sample mount which is thermally decoupled from a scanning stage. It is protected by a radiation shield in order to minimize thermal influence on the surrounding microscope components. A combination of ceramic insulators and point contacts is used to provide thermal impedance between the sample mount and the scanner. No significant temperature increase has been observed at the scanner location when a sample was cooled or heated. The nichrome heater and a calibrated thermometer are mounted next to the sample pin and ensure proper temperature regulation. Figure 8 demonstrates performance of the temperature regulation system. Fig. 8a shows the sample response to a $4 \mathrm{~K}$ temperature step. The settling time is $\sim 10 \mathrm{~min}$; Fig. $8 \mathrm{~b}$ demonstrates the long-term temperature stability. Temperature can be maintained for many hours (100 l nitrogen dewar allows operation for up to one week without refill) with fluctuations less than $20 \mathrm{mK}$. Panels (c) and (d) in Fig. 8 illustrate performance of the high temperature setup. $90 \mathrm{~nm}$ thick chromium dots deposited on a Si substrate for sample fiducialization where imaged using x-ray fluorescence at $800 \mathrm{~K}$. Two identical scans were acquired $1560 \mathrm{~s}$ apart (pixel size $160 \mathrm{~nm}$ ). When comparing relative positions of two dots by calculating their center of mass, we obtained the drifts of $75 \mathrm{~nm}$ in the horizontal and $40 \mathrm{~nm}$ in the vertical direction respectively. Calculations of cross-correlation reveal the drift of $121 \mathrm{~nm}$ horizontally and $46 \mathrm{~nm}$ vertically. The 
system demonstrated good thermal stability, however to fully quantify nm-scale drifts finer features have to be imaged with an adequate pixel size.

\section{Conclusion}

In conclusion, we have designed, constructed and commissioned a high resolution versatile scanning microscope suitable for imaging in the hard $\mathrm{x}$-ray regime. The instrument supports fluorescence, diffraction, absorption, differential phase contrast,

tomography and ptychography imaging techniques and yields $\sim 15 \times 15 \mathrm{~nm}^{2}$ imaging resolution for the MLL microscope module and $25 \times 26 \mathrm{~nm}^{2}$ imaging resolution for the ZP microscope module respectively. The microscope is equipped with a temperature regulation system and allows to vary temperature of a sample in the range of $90 \mathrm{~K}$ $1000 \mathrm{~K}$. The instrument is installed at the HXN beamline of the NSLS-II and is open for a general user community.

\section{Acknowledgements}

This work was performed using resources of the R\&D laboratories and the Hard Xray Nanoprobe (3-ID HXN) beamline of the National Synchrotron Light Source II, a U.S. Department of Energy (DOE) Office of Science User Facility operated for the DOE Office of Science by Brookhaven National Laboratory under Contract No. DESC0012704. YH thanks The Innovation and Application of Nanoscience Thematic Program and the Academia Sinica Thematic Project for support during this work.

\section{References}

Shapiro D. A., Yu Y.-S., Tyliszczak T., Cabana J., Celestre R., Chao W., Kaznatcheev K., David Kilcoyne A. L., Maia F., Marchesini S., Shirley Meng Y., Warwick T., Yang L. L., \& Padmore H. A. (2014). Nat. Photonics 8, 765-769.

Holler M., Guizar-Sicairos M., Tsai E. H. R., Dinapoli R., Müller E., Bunk O, Raabe J. \& Aeppli G. (2017). Nature 543, 402-406.

IUCr macros version 2.1.10: 2016/01/28 
Yan H., Nazaretski E., Lauer K., Huang X., Wagner U., Rau C., Yusuf, Robinson I., Kalblfleisch S., Li L., Bouet N., Zhou J., Conley R. \& Chu Y. S. (2016). Sci. Reports 6, 1:20112-6:20212.

Liu Y., Meier F., Crest C. M., Webb S. \& Weckhuysen B. M. (2016). Nat. Comm. 7, 12634

Winarski R. P., Holt M. V., Rose V., Fuesz P., Carbaugh D., Benson C., Shu D., Kline D., Stephenson G. B., McNulty I. \& J. Maser (2012). J. Synch. Radiation 19, 1056-1060.

Somogyi A., Medjoubi K, Baranton G, Le Roux V., Ribbens M., Polack F., Philippot P. \& Samama J.-P. (2015). J. Synch. Radiation 22, 1118-1129.

Chen S., Deng J., Yuan Y., Flachenecker C., Mak R., Homberger B., Jin Q., Shu D., Lai B., Maser J., Roehrig C., Paunesku T., Gleber S. C., Vine D. J., Finney L., VonOsinski J., Bolbat M., Spink I., Chen Z., Steele J., Trapp D., Irwin J., Feser M., Snyder E., Brister K., Jacobsen C, Woloschak G. \& Vogt S. (2014). J. Synch. Radiation 21, 66-75.

Mohacsi I., Vartiainen I., Rösner B., Guizar-Sicairos M., Guzenko V. A., McNulty I., Winarski R., Holt M. V. \& David C. (2017). Sci. Reports 7, 7:43624.

Chao W., Fischer P., Tyliszczak T., Rekawa S., Anderson E. \& Naulleau P.(2012). Opt. Express 20, 9777-9783.

Mimura Hidekazu, Handa Soichiro, Kimura Takashi, Yumoto Hirokatsu, Yamakawa Daisuke, Yokoyama Hikaru, Matsuyama Satoshi, Inagaki Kouji, Yamamura Kazuya, Sano Yasuhisa, Tamasaku Kenji, Nishino Yoshinori, Yabashi Makina, Ishikawa Tetsuya \& Yamauchi Kazuto (2010) Nat. Phys. 6, 122-125.

Krueger S. P., Neubauer H., Bartels M., Kalbfleisch S., Giewekemeyer K., Wilbrandt P. J. , Sprung M. \& Salditt T. (2012). J. Synch. Radiation 19, 227-236.

da Silva J. S., Pacureanu A., Yang Y., Bohic S., Morawe C., Barrett R. \& Cloetens P. (2017). Optica 4, 492-495.

Kang H., Yan H., Winarski R., Holt M., Maser J., Liu C., Conley R., Vogt S., Macrander A. \& Stephenson G. B. (2008). Appl. Phys. Lett 92, 221114.

Conley R., Bouet N., Chu Y. S., Huang X., Kang H. C., Macrander A. T., Maser J., Nazaretski E., Stephenson G. B. \& Yan H. (2016). Synch. Radiation News 29, 16-20.

Morgan A. J., Prasciolu M., Andrejczuk A., Krzywinski J., Meents A., Pennicard D., Graafsma H., Barty A., Bean R. J., Barthelmess M., Oberthuer D., Yefanov O., Aquila A., Chapman H. N. \& Bajt S. (2015). Sci. Reports 5, 5:09892.

Yan H., Maser J., Macrander A., Shen Q., Vogt S., Stephenson G. B \& Kang H. C. (2007). Phys. Rev B 76, 115438.

Kubec A., Melzer K., Gluch J., Niese S., Braun S., Patommel J., Burghammer M. \& Leson A. (2017). J. Synch. Radiation 24, 413-421.

Kubec A., Maser J., Formanek P., Franke V., Braun S., Gawlitza P., Leson A. \& Macrander A (2017). Appl. Phys. Lett 110, 111905:1-111905:5.

Yan H., Conley R., Bouet N. \& Chu Y. S (2014). J. of Phys. D - Appl. Phys. 47, 263001.

IUCr macros version 2.1.10: 2016/01/28 
Yan H., Rose V., Shu D., Lima E., Kang H. C., Conley R., Liu C., Jahedi N., Macrander A. T., Stephenson G. B., Holt M., Chu Y. S., Lu M. \& Maser J. (2011). Opt. Express 19, 15069-15076.

Yan H., Maser J., Kang H. C., Macrander A. \& Stephenson G. B. (2008). Proc. SPIE - Int. Soc. Opt. Eng. 7077, 70770.

Mesaros, A., Fujita K., Eisaki H., Uchida S., Davis J. S., Sachdev S., Zaanen J., Lawler M. J. \& Kim Eun-Ah (2011) Science 333, 426-430.

Nazaretski, E., Graham K. S., Thompson J. D., Wright J. A., Pelekhov D. V., Hammel P. C. \& Movshovich R. (2009) Rev. Sci. Instr. 80, 83704-83704-6.

Lammle K., Trevethan T., Schwarz A., Watkins M, Shluger A., \& Wiesendanger R.(2010) Nano. Lett. 10, 2965-2971.

Shu D., Nazaretski E., Kim Jungdae., Yan H., Lauer K., Mullany B., Kuhne D., Maser J. \& Chu Y. S. (2013) J. Phys.: Conf. Series 463, 12029-12029-4.

Kim Jungdae, Lauer K, Yan H., Chu Y. S. \& Nazaretski E. (2013). Rev. Sci. Instr. 84, 35006-35005-4.

Nazaretski, E., Kim Jungdae, Yan, H., Lauer K., Eom D., Shu D., Maser J., Pesic Z., Wagner U., Rau C. \& Chu Y. S. (2013). Rev. Sci. Instr. 84, 33701-33701-7.

Nazaretski E., Huang X., Yan H., Lauer K., Conley R., Bouet N. Zhou J., Xu W., Eom D., Legnini D., Harder R., Lin C.-H., Chen Y.-S., Hwu Y., \& Chu Y. S. (2014) Rev. Sci. Instr. 85, 33707-33707-5.

Hwu En-Te, Nazaretski E. Chu Y. S., Chen H.-H., Chen Y.-S., Xu Weihe \& Hwu Y. (2013). Rev. Sci. Instr. 84, 123702-123702-8.

Nazaretski E., Lauer K., Yan H., Bouet N., Zhou J., Conley R., Huang X., Xu W., Lu M., Gofron K., Kalbfleisch S., Wagner U., Rau C. \& Chu Y. S. (2015). J. Synch. Radiation 22, 336-341.

Xu W., Lauer K., Chu Y. S. \& Nazaretski E. (2014). J. Synch. Radiation 21, 1367-1369.

Huang X., Yang W., Harder R., Sun Y., Lu M., Chu Y. S., Robinson I. K. \&, Mao Ho-kwang (2015). Nano Letters 15, 7644-7649.

Uhlir V., Urbanek M., Hladik L., Spousta J., Im M.-Y., Fischer P., Eibagi N., Kan J. J., Fullerton E. E. \& Sikola T. (2013). Nat. Nanotechnology 18, 341-346.

Deng J., Vine D. J., Chen S., Nashed Y. S. G., Jin Q, Phillips N. W., Peterka T., Ross R., Vogt S. \& Jacobsen C. J. (2015 Proc. Natl. Acad. Sci. 8, 2314-2319.

IUCr macros version 2.1.10: 2016/01/28 


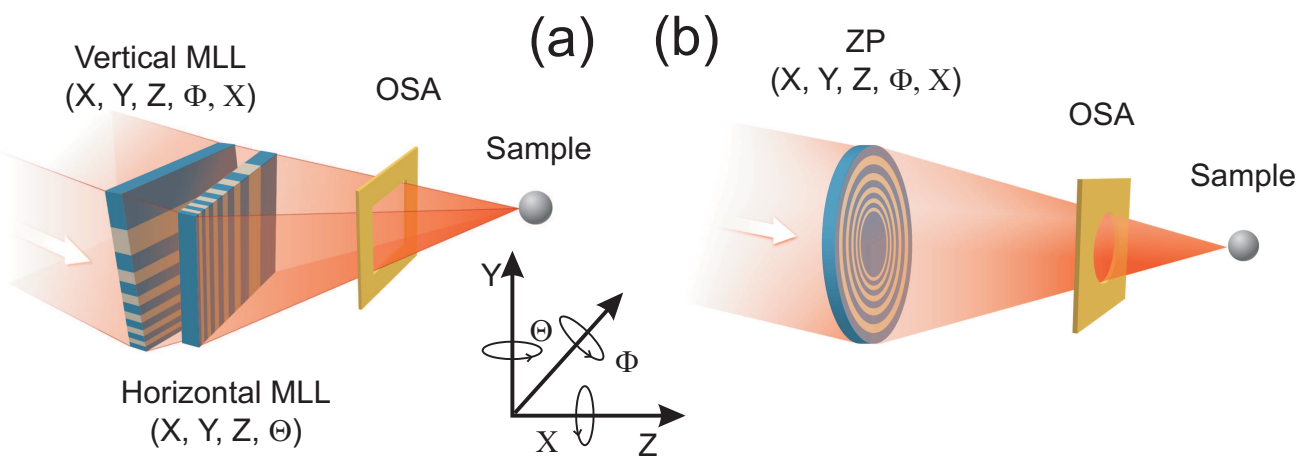

Fig. 1. Two types of the nanofocusing optics implemented in the HXN microscope. (a) represents Multilayer Laue Lenses (MLLs) and (b) Zone Plate optics respectively. For MLLs two linear optics have to be aligned orthogonally with respect to each other to achieve point focusing. Degrees of motion required to perform optics alignment and manipulation are depicted.
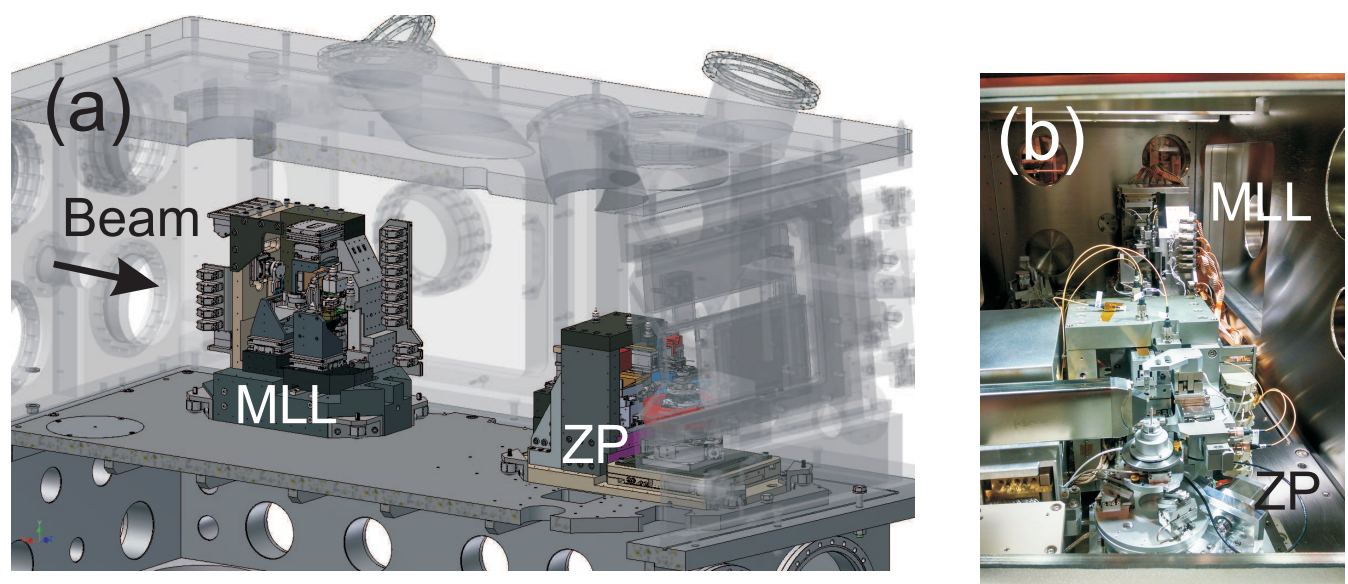

Fig. 2. (a) Demonstration of a modular concept of the instrument, MLL and ZP microscope modules are shown inside the vacuum chamber. (b) the actual photograph of two modules, ZP microscope module in the front and the MLL module is parked in the back (upstream) of the chamber. 

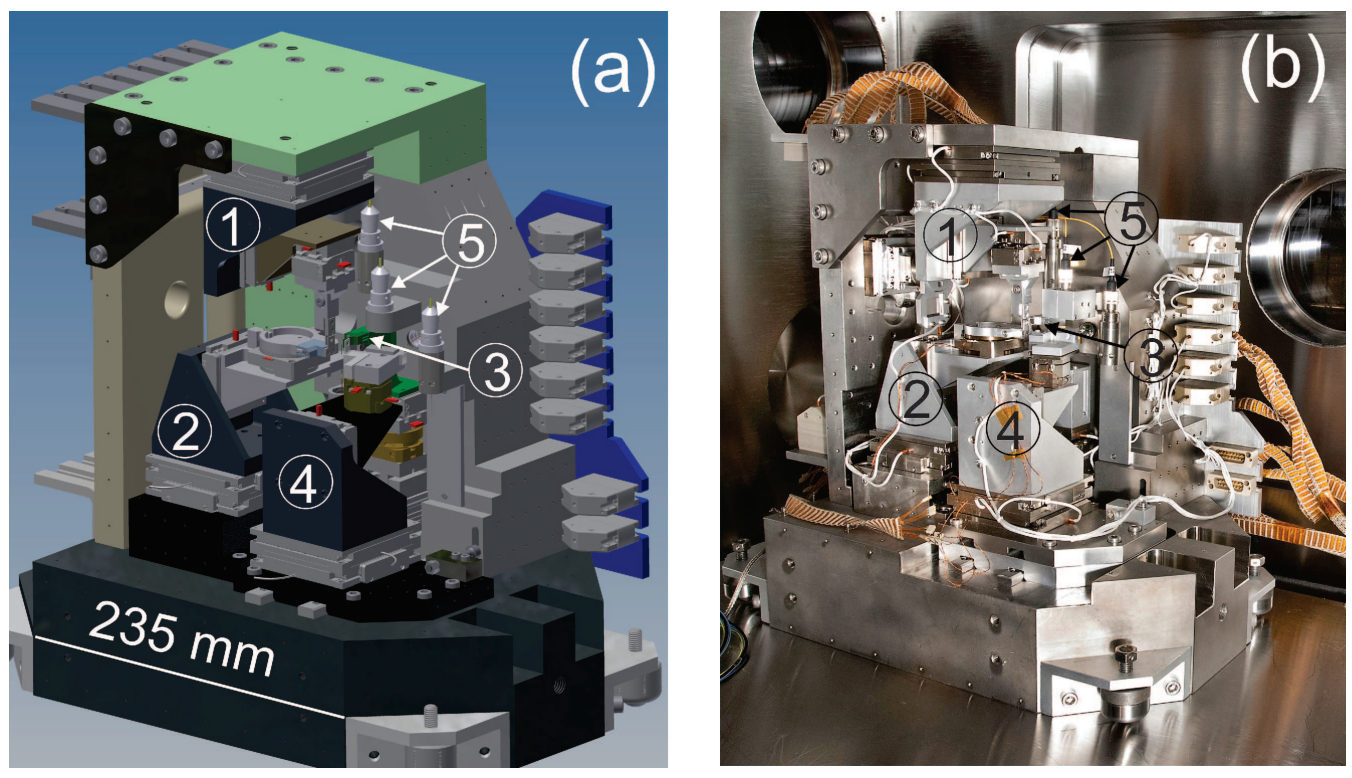

Fig. 3. (a) Computer Aided Design (CAD) model of the MLL module. Key components are enumerated: 1 - vertical MLL assembly, 2- horizontal MLL assembly, 3 OSA assembly, 4 - sample stage assembly, 5 - fiber optic interferometers heads. (b) Photograph of the assembled module inside the vacuum chamber.
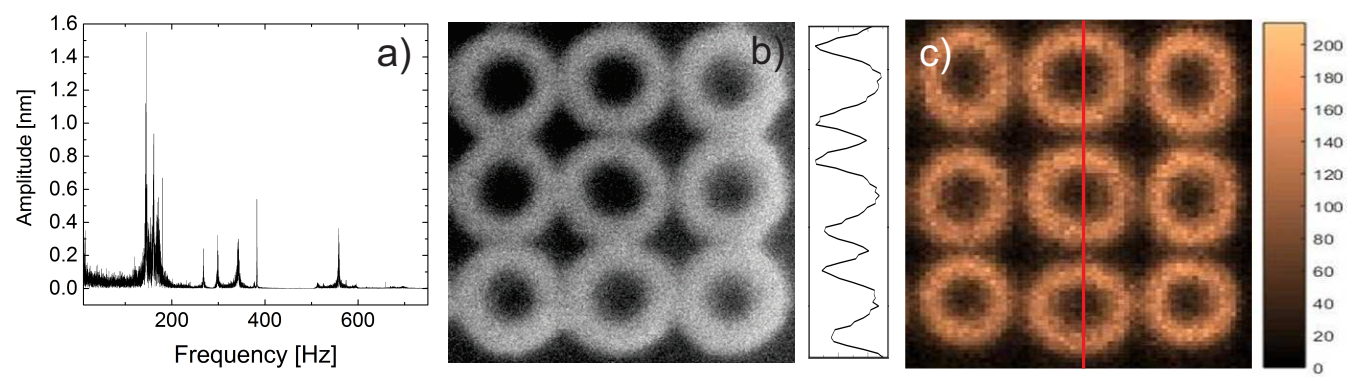

Fig. 4. (a) FFT spectrum of the fully loaded sample stage in the x-direction, all resonances are above $100 \mathrm{~Hz}$. (b) SEM image of the Pt test pattern. Donuts are 80 $\mathrm{nm}$ in diameter and $20 \mathrm{~nm}$ line width. The height of the rings is $200 \mathrm{~nm}$. (c) XRF image (platinum L-edge) of the same test pattern, x-ray energy $12 \mathrm{keV}$, exposure time $0.2 \mathrm{~s}, 5 \mathrm{~nm}$ per pixel. Scan profile along the vertical line is shown on the left and demonstrates achieved spatial resolution. 

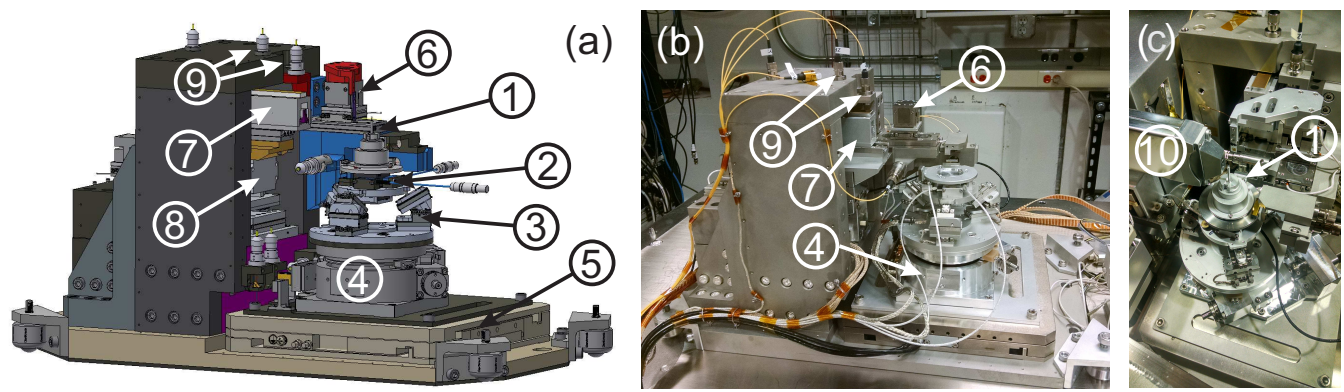

Fig. 5. (a) CAD model of the ZP microscope module, key components are enumerated. 1 - sample mount, 2 - sample scanner with capacitive position readout, 3 - parallel kinematic Smarpod device, 4 - sample rotary stage, 5 - sample base stages, 6 OSA assembly, 7 - ZP carriage, 8 - ZP manipulation assembly, 9 - fiber optics interferometers. (b) photograph of the $\mathrm{ZP}$ microscope module. (c) photograph of the $\mathrm{ZP}$ microscope module with the sample mounted, 10 - fluorescence detector.
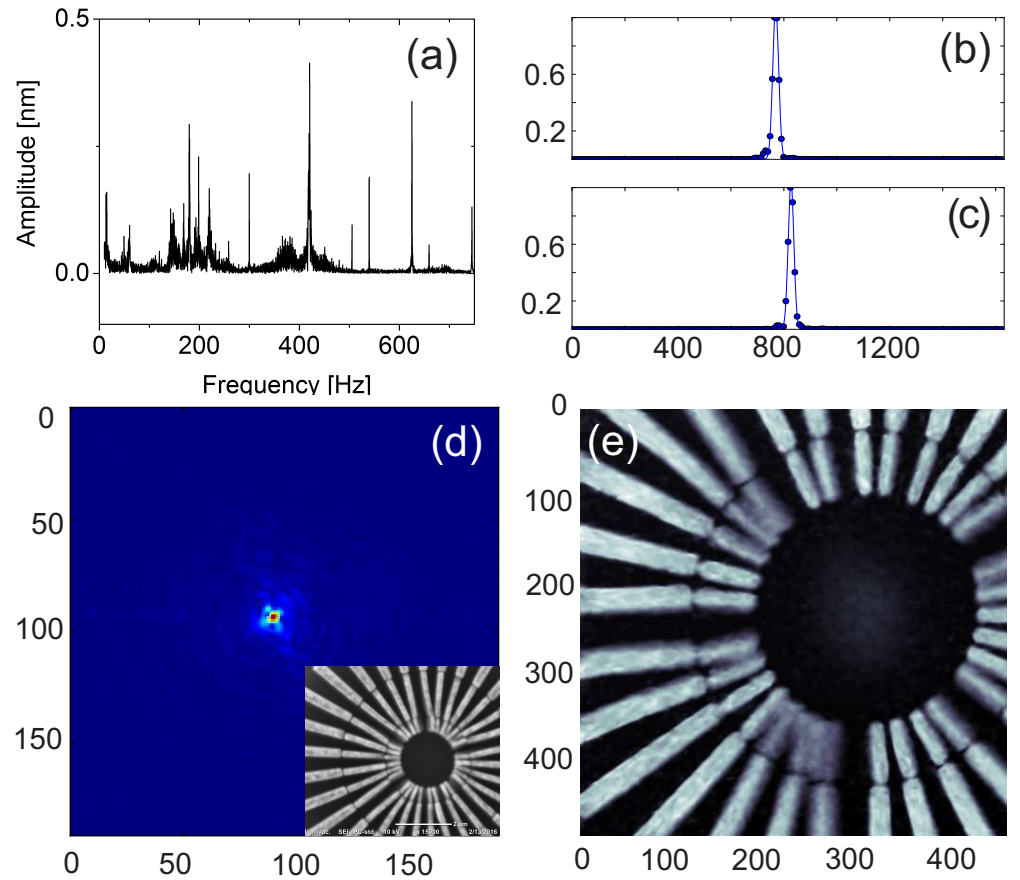

Fig. 6. (a) FFT spectrum of the sample stage in the X - direction. (b),(c) Gaussian fittings of horizontal and vertical line plots give full-width-at-half-maximum focus sizes of $26 \mathrm{~nm}$ and $25 \mathrm{~nm}$, respectively. (d) The reconstructed focused beam. (e) The reconstructed phase of a star test pattern. The width of the finest inner spokes is $100 \mathrm{~nm}$. Some of the inner spokes have collapsed (the thickness of an Au test pattern is $800 \mathrm{~nm}$ ), which can be also seen in the SEM image, shown as an inset in panel (d). 

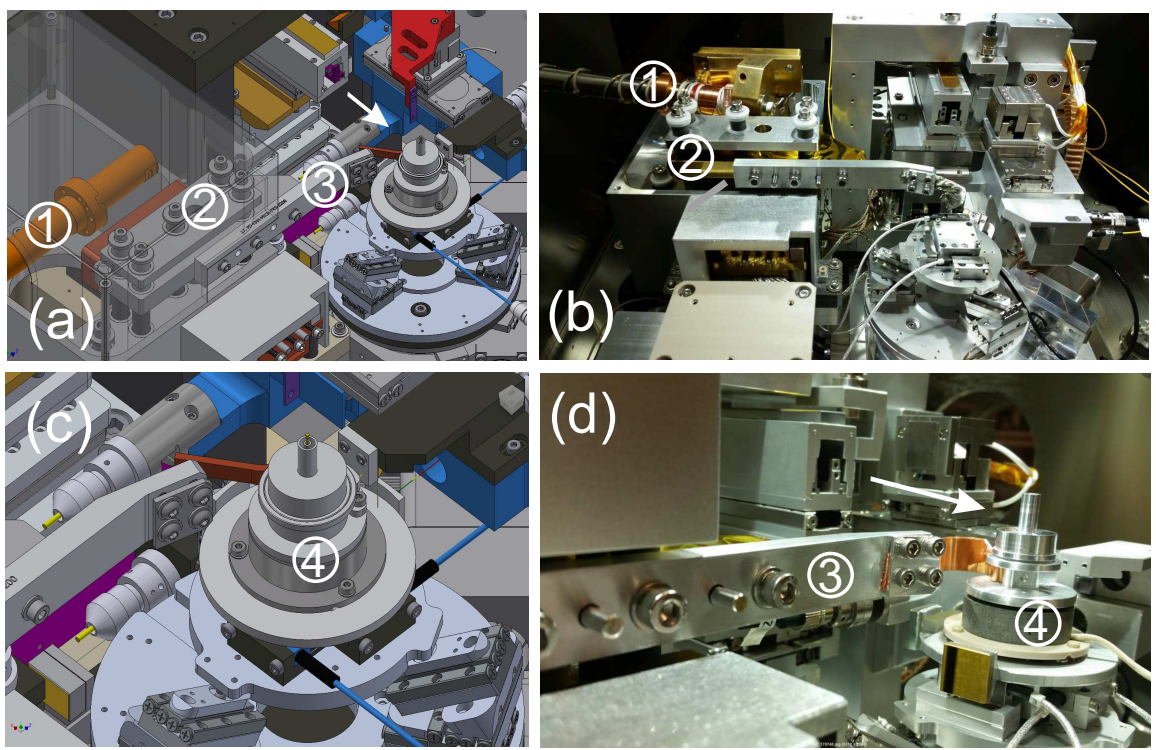

Fig. 7. (a), (c) CAD models of a temperature regulation system, major components are numbered. 1 - cold finger of a cryostat, 2 - vibration isolation platform, 3 - cooling arm with attached cooling stripes (copper in this particular case), 4 - sample holder assembly. (b), (d) photographs of the installed system, beam direction is shown with an arrow. 

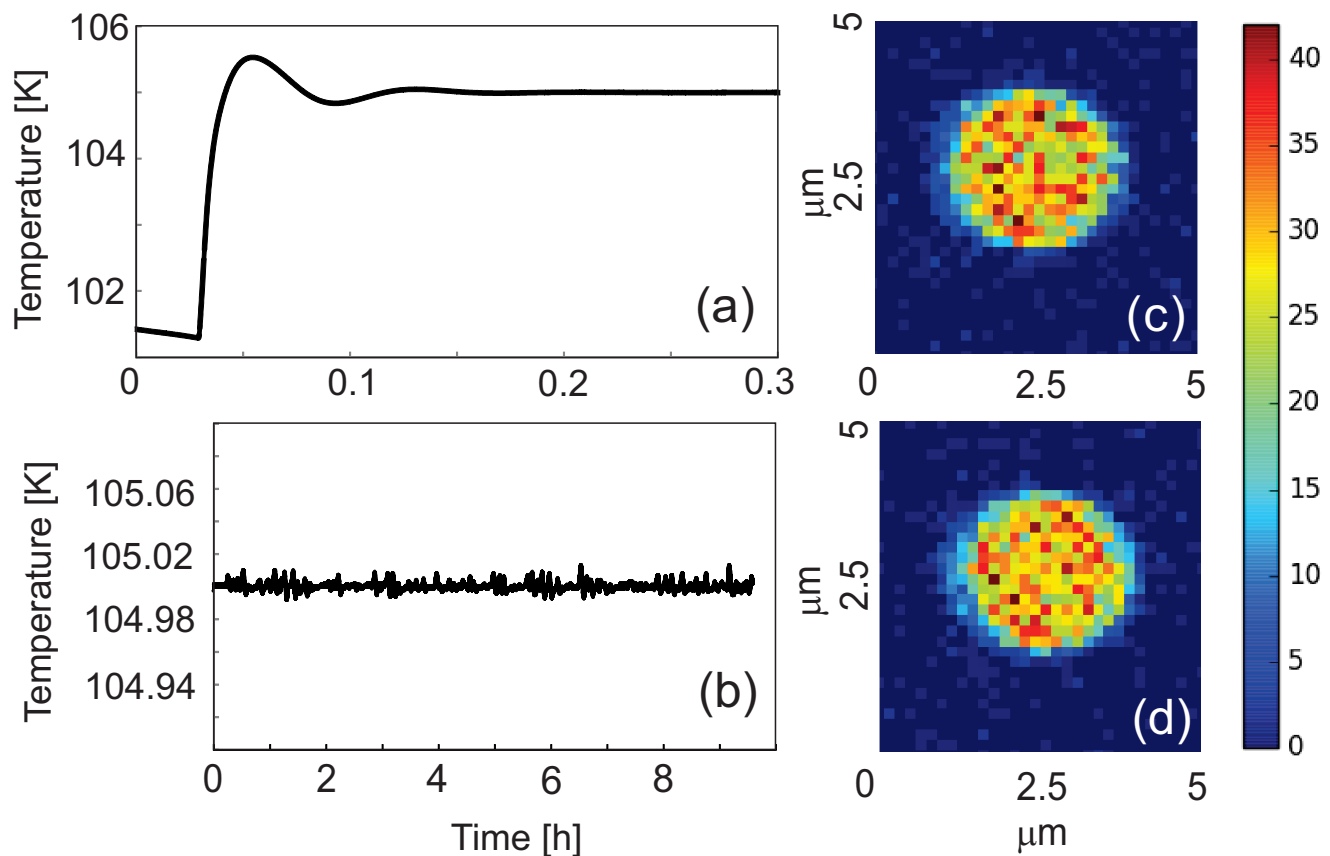

Fig. 8. (a) Response of the temperature regulation system to a $4 \mathrm{~K}$ step at cryogenic temperatures (PID parameters are not fully optimized). (b) stability of the sample temperature over 10 hours time period. (c), (d) fluorescence images of a $\mathrm{Cr}$ dot, T $=800 \mathrm{~K}$, photon energy $11.95 \mathrm{keV}$, pixel size $160 \mathrm{~nm}$. Time delay between data shown in (c) and (d) equals $1560 \mathrm{~s}$.

\section{Synopsis}

MLL-based X-ray scanning microscope installed at the Nanoprobe beamline of the National Synchrotron Light Source II 